\title{
ANALISA MODEL SUPPORT VECTOR MACHINE TEXTMINING PADA KOMENTAR POSITIF DAN NEGATIF UNTUK REVIEW PERBANDINGAN WHATSAPP VS BBM
}

\author{
Agus darmawan $^{1}$, Syamsiah $^{2}$ \\ Program Studi Teknik Informatika, Universitas Indraprasta PGRI 1,2 \\ Email: agus.darmawan@ymail.com ${ }^{1}$ \\ Email: ncham.unindra08@gmail.com²
}

\begin{abstract}
Abstrak
Sebagai pengguna smartphone, akhir-akhir ini kita dibuat pusing oleh munculnya beberapa layanan instant messaging lintas platform mobile yang kelihatannya dalam waktu singkat dapat menjadi sangat populer. Mulai dari Whatsapp dan $B B M$ rasanya saat ini sedang bersaing ketat dalam memperebutkan perhatian para pengguna smartphone. Sebelum kita memutuskan untuk menggunakan instant messaging, ada hal dapat dipelajari dari hasil komentar review perbadingan Whatsapp dan BBM. Membaca komentar review tersebut secara keseluruhan dapat memakan waktu, namun jika hanya sedikit komentar review yang dibaca evaluasi akan menjadi bias. Dari beberapa teknik tersebut yang paling sering digunakan untuk klasifikasi data adalah Support Vector Machines (SVM). SVM memiliki kelebihan yaitu mampu mengidentifikasi dengan hyperplane terpisah yang memaksimalkan margin antara dua kelas yang berbeda. Penelitian ini menghasilkan klasifikasi teks dalam bentuk positif atau negatif dari review layanan instant messaging lintas platform mobile. Pengukuran berdasarkan akurasi Support Vector Machines, sedangkan pengukuran akurasi diukur dengan confusion matrix dan kurva ROC. Hasil penelitian menunjukkan akurasi Support Vector Machines dari $71.00 \%$.
\end{abstract}

Kata Kunci: Komentar, SVM, BBM, Whatsapp, Confusion Matrix, Kurva ROC

\section{Pendahuluan}

Persaingan layanan chatting di smartphone belakangan ini mencapai puncaknya setelah salah satu producent smartphone berhasil menjual produknya ke seluruh dunia lantaran aplikasi messaging yang ditanamkan didalamnya memberi sensai berbeda dari pada layanan chatting yang beredar di internet selama ini. Menjamurnya penggunaan aplikasi messaging di beberapa tahun belakangan ini dikarenakan beberapa faktor diantaranya Fenomena social messaging, sifat multi platform, sebagai alat komunikasi yang sederhana dan mudah dipakai serta dibawa kemana saja. Hal ini yang menjadikan Aplikasi messaging akhir-akhir ini menjadi aplikasi wajib install (harus ada) bagi pengguna smartphone. Di tanah air, setidaknya sampai saat ini ada empat aplikasi yang bersaing ketat. Mulai dari BBM, Whatsapp, Line, Kakao Talk dan WeChat. Memang masih ada beberapa lagi layanan sejenis. Namun tidak semua Aplikasi messaging memiliki kualitas yang baik untuk menunjang kebutuhan konsumen dan hal ini yang harus diperhatikan oleh para konsumen. Sebelum konsumen memutuskan untuk mengunakan Layanan Aplikasi messaging yang baik, sebaiknya konsumen mengetahui dengan Keunggulan dari Layanan Aplikasi messaging tersebut, hal ini dapat dipelajari dari testimoni dan opini atau hasil komentar review perbadingan dari whatsapp dan BBM. Saat ini konsumen yang menulis opini dan pengalaman secara online semakin meningkat. Membaca komentar review tersebut secara keseluruhan dapat memakan waktu, namun jika hanya sedikit komentar review yang dibaca evaluasi akan menjadi bias. Klasifikasi sentimen bertujuan untuk mengatasi masalah ini dengan secara otomatis mengelompokkan review pengguna menjadi opini positif atau negatif (Z. Zhang et al., 2011). Dari beberapa teknik klasifikasi sentimen tersebut yang paling sering digunakan untuk klasifikasi data adalah Support Vector Machines (SVM). SVM merupakan metode supervised learning yang menganalisa data dan mengenali pola-pola yang digunakan untuk klasifikasi (Basari et all: 2013). Support Vector Machines (SVM) adalah kasus khusus 
dari keluarga algoritma yang disebut sebagai regularized metode klasifikasi linier dan metode yang kuat untuk meminimalisasi resiko (Weiss et al., 2010). SVM memiliki kelebihan yaitu mampu mengidentifikasi hyperplane terpisah yang memaksimalkan margin antara dua kelas yang berbeda (Chou et al., 2014). Namun Support Vector Machine (Basari et al., 2013). Pada penelitian ini algoritma Support Vector Machines diterapkan oleh penulis untuk mengklasifikasikan teks pada komentar review perbadingan antara wahtsaap dan BBM dalam rangka meningkatkan akurasi analisa sentimen.

\section{Tinjauan Pustaka}

Review Perbandingan BlackBerry Messenger Vs WhatsApp

Situs web adalah wadah bagi beragam pendapat. Salah satu bentuk opini yang memiliki kredibilitas adalah review produk. Situs web seperti amazon.com mendorong pengguna untuk memberikan ulasan (review) (Weiss et al., 2010). Hasil penambangan teks dari review tersebut dapat diklasifikasikan dengan tiga kategori, yaitu positif, negatif dan netral. Menurut Zhang dan Liu dalam (Khan et al., 2014) analisis mendalam dari setiap aspek produk berdasarkan pendapat konsumen adalah sama pentingnya bagi masyarakat, para pedagang dan produsen. Selain di amazon.com, epinions.com maupun Kaskus.com merupakan jenis situs lain yang berisikan Perbandingan BlackBerry Messenger Vs WhatsApp.

\section{Analisa Sentimen (Sentiment Analysis)}

Menurut Tang dalam Haddi (Haddi et al., 2013), analisa sentimen pada review adalah proses menyelidiki review produk di internet untuk menentukan opini atau perasaan terhadap suatu produk secara keseluruhan. Menurut Thelwall dalam Haddi (Haddi et al., 2013), analisa sentimen diperlakukan sebagai suatu tugas klasifikasi yang mengklasifikasikan orientasi suatu teks ke dalam positif atau negatif. Menurut Mejova dalam Basari (Basari et al., 2013), tujuan dari analisa sentimen adalah untuk menentukan perilaku atau opini dari seorang penulis dengan memperhatikan suatu topik tertentu. Perilaku bisa mengindikasikan alasan, opini atau penilaian, kondisi kecenderungan (bagaimana si penulis ingin mempengaruhi pembaca).

\section{Konsep Support vector machine}

Konsep SVM dapat dijelaskan secara sederhana sebagai usaha mencari hyperplane terbaik yang berfungsi sebagai pemisah dua buah class pada input space. Untuk dimensional space, input data $\mathrm{x}(\mathrm{i}=1 \ldots \mathrm{k})$, dimana milik kelas 1 atau kelas 2 dan label yang terkait menjadi -1 untuk kelas 1 dan +1 untuk kelas 2 . Gambar di bawah ini memperlihatkan beberapa pattern yang merupakan anggota dari dua buah class: positif (dinotasikan dengan +1 ) dan negatif (dinotasikan dengan -1). Pattern yang tergabung pada class negatif disimbolkan dengan kotak, sedangkan pattern pada class positif, disimbolkan dengan lingkaran. Jika data input dapat dipisahkan secara linear, pemisahan hyperplane dapat diberikan dalam:
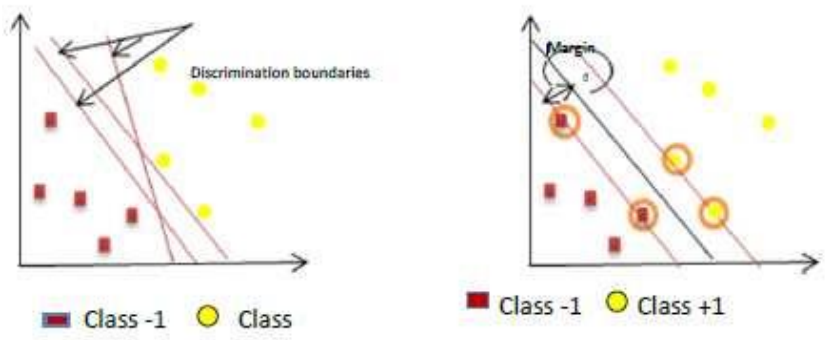

\section{Gambar 1. SVM berusaha menemukan Hyperplane terbaik yang memisahkan kedua class negatif dan positif (Nugroho, 2008)}

Tujuan dari SVM adalah untuk memisahkan data kelas dengan cara maksimal margin hyperplane. Dengan demikian, SVM menjamin untuk memaksimalkan jarak antara data 
yang paling dekat dengan hyperplane. Jika input data dapat dipisahkan secara linear, pemisahan hyperplane dapat diberikan dalam persamaan:

$$
\mathrm{f}(X)=w^{\mathrm{T}} x+b(3)
$$

dimana $w$ adalah n- mensi bobot vektor dan $b$ adalah pengali skalar atau nilai bias. Persamaan ini menemukan maksimum margin untuk memisahkan kelas dari kelas positif dari kelas negatif. Fungsi keputusan ditunjukkan dalam persamaan. Contoh untuk data linear terpisah ditunjukkan pada Gambar 1:

$$
\mathrm{y}_{\mathrm{i}}\left(\mathrm{w} \cdot \mathrm{x}_{\mathrm{i}}+\mathrm{b}\right) \geq 1 i=1 . . \mathrm{k}
$$

\section{Metodologi Penelitian}

\section{Perancangan Penelitian}

Metode penelitian yang penulis lakukan adalah metode penelitian eksperimen, dengan tahapan sebagai berikut:

1. Pengumpulan Data

Data untuk eksperimen ini dikumpulkan, lalu diseleksi dari data yang tidak sesuai.

2. Pengolahan Awal Data

Model dipilih berdasarkan kesesuaian data dengan metode yang paling baik dari beberapa metode pengklasifikasian teks yang sudah digunakan oleh beberapa peneliti sebelumnya. Model yang digunakan adalah algoritma Support Vector Machine (SVM).

3. Metode Yang Diusulkan

Untuk meningkatkan akurasi dari Algoritma Support Vector Machine (SVM). maka dilakukan penambahan tahapan preprocessing.

4. Eksperimen dan Pengujian Metode

Untuk eksperimen data penelitian, penulis menggunakan RapidMiner untuk mengolah data. Sedangkan untuk pengujian metode, penulis membuat aplikasi menggunakan bahasa pemrograman PHP dengan perangkat lunak Adobe Dreamweaver sebagai editor.

5. Evaluasi dan Validasi Hasil

Evaluasi dilakukan untuk mengetahui akurasi dari model algoritma Support Vector Machine (SVM). Validasi digunakan untuk melihat perbandingan hasil akurasi dari model yang digunakan dengan hasil yang telah ada sebelumnya. Teknik validasi yang digunakan adalah cross validation.

\section{Analisis Data}

\section{Pengumpulan Data}

Penulis menggunakan data komentar review produk smartphone yang dikumpulkan dari situs http://www.kaskus.co.id/thread. Data terdiri dari 50 komentar review positif dan 50 komentar review negatif. Penulis mengunduh data tersebut dari http://www.kaskus.co.id/thread/523c00edfcca174a4a00000f/blackberry-messenger-vswhatsapp-bagus-mana/. Contoh komentar review positif sebagai berikut:

"Kalau menurut saya:

- bbm lebih ke segi komunikasi

- whatsapp lebih ke segi hiburan dan entertainment"

Sedangkan contoh komentar review negatif sebagai berikut:

"setuju gan!

Tp whatsapp buat komunikasi oke juga kok.

Kapok ane pake bbm" 


\section{Pengolahan Awal Data}

Untuk mengurangi lamanya waktu pengolahan data, penulis hanya menggunakan 50 komentar review positif dan komentar 50 komentar review negatif sebagai data training.

Dataset ini dalam tahap preprocessing harus melalui 5 (tiga) proses, yaitu:

1. Tokenization

Dalam proses tokenization ini, semua kata yang ada di dalam tiap dokumen dikumpulkan dan dihilangkan tanda bacanya, serta dihilangkan jika terdapat simbol atau apapun yang bukan huruf.

2. Filter Tokens (by Length)

Dalam proses ini, kata-kata yang memiliki pajang kurang dari 4 dan lebih dari 25 akan dihapus, seperti kata yg,ane, gan yang merupakan kata-kata yang tidak mempunyai makna tersendiri jika dipisahkan dengan kata yang lain dan tidak terkait dengan kata sifat yang berhubungan dengan sentimen.

3. Stopwords Removal

Dalam proses ini, kata-kata yang tidak relevan akan dihapus, seperti kata tetapi, untuk, dengan, yang merupakan kata-kata yang tidak mempunyai makna tersendiri jika dipisahkan dengan kata yang lain dan tidak terkait dengan kata sifat yang berhubungan dengan sentimen

4. Transform Case

Dalam proses ini, kata-kata yang tidak relevan akan diubah, seperti kata yang mengandung huruf besar yang diubah menjadi huruf kecil sehingga dapat saling berhubungan dengan sentimen.

5. Stemming

Dalam proses ini kata-kata akan dikelompokkan ke dalam beberapa kelompok yang memiliki kata dasar yang sama, seperti hibur, hiburan, menghibur, di mana kata dasar dari semuanya adalah kata hibur.

Sedangkan untuk tahap transformation dengan melakukan pembobotan TF-IDF pada masing-masing kata. Di mana prosesnya menghitung kehadiran atau ketidakhadiran sebuah kata di dalam dokumen. Berapa kali sebuah kata muncul di dalam suatu dokumen juga digunakan sebagai skema pembobotan dari data tekstual.

\section{Metode Yang Diusulkan}

Metode yang penulis usulkan adalah penggunaan 1 (satu) metode pemilihan fitur agar akurasi pengklasifikasi Support Vector Machines (SVM) bisa digunakan. Penulis menggunakan pengklasifikasi Support Vector Machines karena merupakan teknik machine learning yang populer untuk klasifikasi teks, serta memiliki performa yang baik pada banyak domain. SVM memiliki kelebihan yaitu mampu mengidentifikasi hyperplane terpisah yang memaksimalkan margin antara dua kelas yang berbeda. SVM menjamin untuk memaksimalkan jarak antara data yang paling dekat dengan hyperplane. Jika input data dapat dipisahkan secara linear. Lihat gambar 3. untuk model yang diusulkan secara lebih detail. 


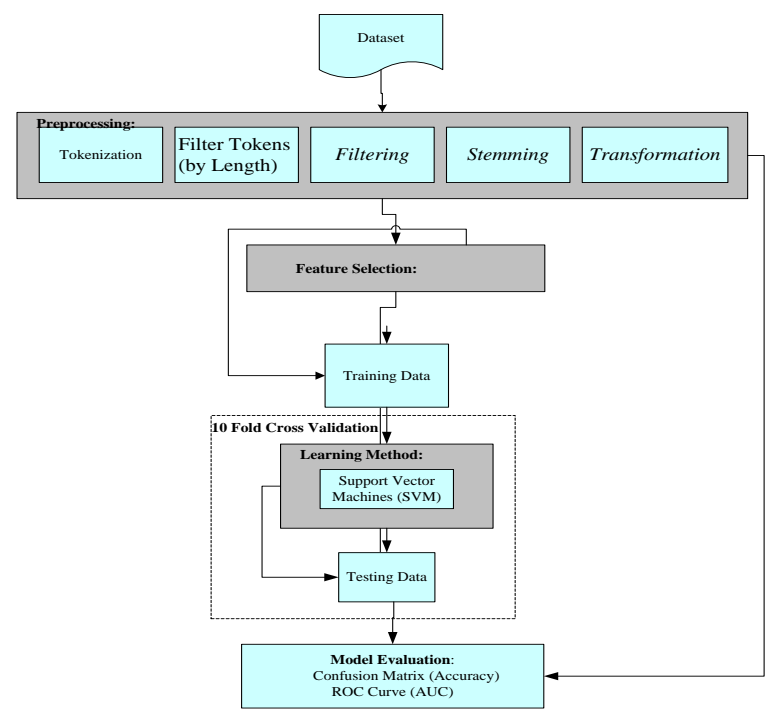

Gambar 2. Model yang Diusulkan

Data harus melalui tahap preprocessing terlebih dahulu agar didapatkan kata-kata relevan untuk diklasifikasi. Proses evaluasi dilakukan menggunakan 10 Fold Cross Validation. Pengukuran akurasi diukur dengan Confusion Matrix.Hasil yang adalah akurasi Support Vector Machines (SVM).

\section{Hasil dan Pembahasan}

\section{Klasifikasi Teks Menggunakan Support Vector Machine}

Data training yang digunakan dalam pengklasifikasian teks ini terdiri dari 50 komentar review positif dan 50 komentar review negatif, berikut adalah tahapan prosesnya:

\section{Pengumpulan Data}

Data komentar review positif disatukan dalam folder dengan nama pos. Sedangkan data komentar review negatif disatukan penyimpanannya dalam folder dengan nama neg. Tiap dokumen berekstensi txt yang dapat dibuka menggunakan aplikasi Notepad.

\section{Pengolahan Awal Data}

\section{a. Tokenization}

Dalam proses tokenization ini, semua kata yang ada di dalam tiap dokumen dikumpulkan dan dihilangkan tanda bacanya, serta dihilangkan jika terdapat simbol atau apapun yang bukan huruf. Berikut adalah contoh hasil dari proses tokenization dalam RapidMiner. Tabel 1 menunjukkan hasil perbandingan teks sebelum dan sesudah dilakukan proses tokenization.

Tabel 1. Perbandingan teks sebelum dan sesudah dilakukan proses tokenization

\begin{tabular}{|c|c|c|}
\hline No & Teks Sebelum & Teks Sesudah \\
\hline 1. & $\begin{array}{l}\text { Teks data komentar } \\
\text { review sebelum dilakukan } \\
\text { proses tokenization }\end{array}$ & $\begin{array}{l}\text { Kalau menurut ane gan: } \\
\text { - whatsapp lebih untuk komunikasi } \\
\text { - tetapi BBM lebih umtuk Hiburan dan } \\
\text { Entertainment }\end{array}$ \\
\hline 2. & $\begin{array}{l}\text { Teks data komentar } \\
\text { review setelah dilakukan } \\
\text { proses tokenization }\end{array}$ & $\begin{array}{l}\text { Kalau menurut ane gan whatsapp lebih } \\
\text { untuk komunikasi tetapi BBM lebih untuk } \\
\text { Hiburan dan Entertainment }\end{array}$ \\
\hline
\end{tabular}

\section{b. Filter Tokens (by Length)}

Dalam proses ini, kata-kata yang memiliki pajang kurang dari 4 dan lebih dari 25 akan dihapus, seperti kata yg,ane, gan yang merupakan kata-kata yang tidak 
mempunyai makna tersendiri jika dipisahkan dengan kata yang lain dan tidak terkait dengan kata sifat yang berhubungan dengan sentimen. Tabel.2 men.unjukkan hasil perbandingan teks sebelum dan sesudah dilakukan proses Filter Tokens.

Tabel 2. Perbandingan Teks Sebelum dan Sesudah Dilakukan Proses Filter Tokens

\begin{tabular}{lll}
\hline No & \multicolumn{1}{c}{ Teks Sebelum } & \multicolumn{1}{c}{ Teks Sesudah } \\
\hline 1. & Teks data komentar review sebelum & Kalau menurut ane gan whatsapp lebih untuk \\
& dilakukan proses filter tokens & $\begin{array}{l}\text { komunikasi tetapi BBM lebih untuk Hiburan } \\
\text { dan Entertainment }\end{array}$ \\
2. & Teks data komentar review setelah & $\begin{array}{l}\text { Kalau menurut whatsapp lebih untuk } \\
\text { dilakukan proses filter tokens }\end{array}$ \\
& komunikasi tetapi BBM lebih untuk Hiburan \\
& Entertainment \\
\hline
\end{tabular}

\section{c. Stopwords}

Dalam proses ini, kata-kata yang tidak relevan akan dihapus, seperti kata tetapi, untuk, dengan, yang merupakan kata-kata yang tidak mempunyai makna tersendiri jika dipisahkan dengan kata yang lain dan tidak terkait dengan kata sifat yang berhubungan dengan sentimen. Tabel 3 menunjukkan hasil perbandingan teks sebelum dan sesudah dilakukan proses stopword removal.

Tabel 3. Perbandingan Teks Sebelum dan Sesudah Dilakukan Proses Stopwords

\begin{tabular}{lll}
\hline No & \multicolumn{1}{c}{ Teks Sebelum } & \multicolumn{1}{c}{ Teks Sesudah } \\
\hline 1. & Teks data komentar review sebelum & Kalau menurut whatsapp lebih untuk \\
& dilakukan proses Stopwords Removal & $\begin{array}{l}\text { komunikasi tetapi BBM lebih untuk Hiburan } \\
\text { Entertainment } \\
\text { 2. }\end{array}$ \\
& Teks data komentar review setelah & mentsapp komunikasi BBM Hiburan \\
& dilakukan proses Stopwords Removal & Entertainment \\
\hline
\end{tabular}

\section{d. Transform Cases}

Dalam proses ini, kata-kata yang tidak relevan akan diubah, seperti kata yang mengandung huruf besar yang diubah menjadi huruf kecil sehingga dapat saling berhubungan dengan sentimen. Tabel 4 menunjukkan hasil perbandingan teks sebelum dan sesudah dilakukan proses transform cases.

\section{Tabel 4. Perbandingan Teks Sebelum dan Sesudah Dilakukan Proses Transform}

\section{Cases}

\begin{tabular}{|c|c|c|}
\hline No & Teks Sebelum & Teks Sesudah \\
\hline 1. & $\begin{array}{l}\text { Teks data komentar review sebelum dilakukan } \\
\text { proses transfom cases }\end{array}$ & $\begin{array}{l}\text { menurut whatsapp komunikasi BBM } \\
\text { Hiburan Entertainment }\end{array}$ \\
\hline 2. & $\begin{array}{l}\text { Teks data komentar review setelah dilakukan } \\
\text { proses transform cases }\end{array}$ & $\begin{array}{l}\text { menurut whatsapp komunikasi bbm } \\
\text { hiburan entertainment }\end{array}$ \\
\hline
\end{tabular}

\section{e. Stemming}

proses ini kata-kata akan dikelompokkan ke dalam beberapa kelompok yang memiliki kata dasar yang sama, seperti hibur, hiburan, menghibur, di mana kata dasar dari semuanya adalah kata hibur. Tabel 5 menunjukkan hasil perbandingan teks sebelum dan sesudah dilakukan proses stemming.

Tabel 5. Perbandingan Teks Sebelum dan Sesudah Dilakukan Proses Stemming

\begin{tabular}{lll}
\hline No & \multicolumn{1}{c}{ Teks Sebelum } & \multicolumn{1}{c}{ Teks Sesudah } \\
\hline 1. & $\begin{array}{l}\text { Teks data komentar review sebelum } \\
\text { dilakukan proses Stemming }\end{array}$ & $\begin{array}{l}\text { Menurut whatsapp komunikasi bmm } \\
\text { hiburan entertainment }\end{array}$ \\
2. & $\begin{array}{l}\text { Teks data komentar review setelah } \\
\text { dilakukan proses Stemming }\end{array}$ & $\begin{array}{l}\text { turut whatsapp komunikasi bmm hibur } \\
\text { entertainment }\end{array}$ \\
\hline
\end{tabular}




\section{Klasifikasi}

Proses klasifikasi pada penelitian ini adalah untuk menentukan sebuah kalimat sebagai anggota kelas positif atau kelas negatif berdasarkan nilai perhitungan pembobotan dari rumus SVM yang bernilai 0 . Jika nilai dari bobot lebih besar sama dengan 0 maka diklasifikasikan kedalam kelas positif dan sebaliknya jika nila bobot kurang dari sama dengan 0 maka dapat diklasifikasikan kedalam kelas negatif. Dokumen yang akan dihitung nilai bobotnya dapat dilihat pada tabel 6 .

Tabel 6. Tabel Dokumen yang Dihitung Nilai Bobotnya

\begin{tabular}{llllccccccc}
\hline \multicolumn{3}{c}{ Dokumen } & & \multicolumn{3}{c}{ Atribut } & \multicolumn{3}{c}{ kelas } \\
\cline { 3 - 10 } & & bbm & cinta & whatsapp & milih & benci & murah & \\
\hline $\begin{array}{l}\text { Pos44.txt (saya cinta } \\
\text { karena murah) }\end{array}$ & bbm & gan & 0,667 & 0,667 & 0 & 0 & 0 & 0,667 & positif \\
$\begin{array}{l}\text { Neg3.txt (tidak cinta benci } \\
\text { lebih memilih whatsapp) }\end{array}$ & bbm & 0,667 & 0,667 & 0,667 & 0,667 & 0,667 & 0 & negatif \\
\hline
\end{tabular}

Berikut adalah perhitungan untuk contoh dokumen pos44.txt dengan fungsi sebagai berikut:

$$
\begin{aligned}
\mathrm{W}_{44} & =\mathrm{Y}_{44} \cdot \mathrm{X}_{44} \\
& =1 .(0,667+0,667+0+0+0+0,667) \\
& =2,001
\end{aligned}
$$

Di mana $\mathbf{W}_{\mathbf{4 4}}$ adalah bobot untuk dokumen Pos44.txt yang menentukan klasifikasi kelas positif atau negatif, sedangkan $\mathbf{Y}_{\mathbf{4 4}}$ merupakan nilai label untuk dokumen tersebut di mana $\mathbf{Y}$ hanya bernilai 1 untuk kelas positif dan -1 untuk kelas negatif. $\mathbf{X}_{\mathbf{3}}$ nilai-nilai atribut yang ada pada sebuah dokumen yang ingin dihitung bobotnya dan ditentukan kelasnya. Bobot untuk dokumen Pos44.txt adalah 2,001, maka dokumen tersebut diklasifikasikan kedalam kelas positif.

Berikut adalah perhitungan untuk contoh dokumen Neg3.txt dengan fungsi sebagai berikut:

$$
\begin{aligned}
\mathrm{W}_{3} & =\mathrm{Y}_{3} \cdot \mathrm{X}_{3} \\
& =-1 .(0,667+0+0,667+0,667+0,667+0) \\
& =-3,336
\end{aligned}
$$

Di mana $\mathbf{W}_{\mathbf{3}}$ adalah bobot untuk dokumen pos44.txt yang menentukan klasifikasi kelas positif atau negatif, sedangkan $\mathbf{Y}_{\mathbf{4 4}}$ merupakan nilai label untuk dokumen tersebut di mana $\mathbf{Y}$ hanya bernilai 1 untuk kelas positif dan -1 untuk kelas negatif. $\mathbf{X}_{\mathbf{3}}$ nilai-nilai atribut yang ada pada sebuah dokumen yang ingin dihitung bobotnya dan ditentukan kelasnya. Bobot untuk dokumen Neg44.txt adalah - 3,336, maka dokumen tersebut diklasifikasikan kedalam kelas negatif. Perhitungan Desain model Support Vector Machine (SVM) dapat dilihat pada gambar 4.

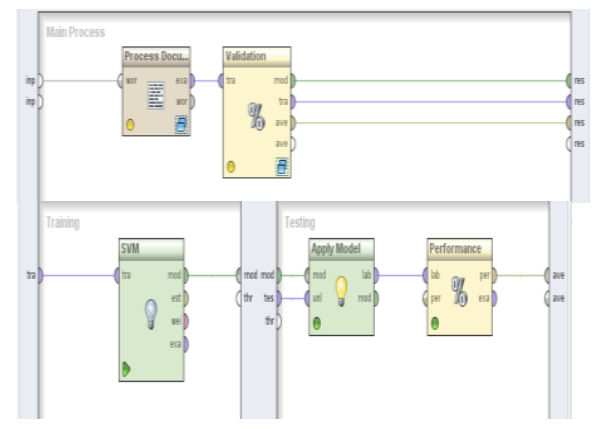

Gambar 3. Desain Model Support Vector Machine (SVM) Menggunakan RapidMiner

\section{Pengujian Model dengan 10 Fold Cross Validation}

Pada penelitian ini, penulis melakukan pengujian model dengan menggunakan teknik 10 cross validation, di mana proses ini membagi data secara acak ke dalam 10 bagian. Proses pengujian dimulai dengan pembentukan model dengan data pada bagian pertama. Model 
yang terbentuk akan diujikan pada 9 bagian data sisanya. Setelah itu proses akurasi dihitung dengan melihat seberapa banyak data yang sudah terklasifikasi dengan benar.

\section{Pembahasan}

Dengan memiliki model klasifikasi komentar review, dapat digunakan untuk menindak lanjuti suatu strategi konsumen memutuskan untuk mengunakan whatsapp atau BBM, yaitu dengan mengidentifikasi komentar review tersebut sentimen yang positif maupun yang negatif. Dari data komentar review yang sudah ada, dipisahkan menjadi kata-kata, lalu diberikan bobot pada masing-masing kata tersebut. Dapat dilihat kata mana saja yang berhubungan dengan sentimen yang sering muncul dan mempunyai bobot paling tinggi. Dengan demikian dapat diketahui komentar review tersebut positif atau negatif. Dalam penelitian ini, hasil pengujian model akan dibahas melalui confusion matrix untuk menunjukkan seberapa baik model yang terbentuk. algoritma Support Vector Machine (SVM) sendiri sudah menghasilkan nilai akurasi $71.00 \%$ dan nilai AUC 0.862 seperti yang bisa dilihat pada tabel 7 .

Tabel 7. Model Algoritma Support Vector Machine (SVM)

\begin{tabular}{llc}
\hline No & Algoritma Support Vector Machine (SVM) & Nilai \\
\hline 1. & Sukses klasifikasi komentar review positif & 44 \\
2. & Sukses klasifikasi komentar review negatif & 27 \\
3. & Akurasi Model & $71.00 \%$ \\
4. & AUC & 0.862 \\
\hline
\end{tabular}

\section{Pengukuran dengan Confusion Matrix}

Pengukuran dengan confusion matrix di sini akan menampilkan perbandingan dari hasil akurasi model Support Vector Machine (SVM) bisa dilihat pada tabel 9.

Table 9. Confusion Matrix Model Support Vector Machine (SVM)

\begin{tabular}{ccccc}
\hline No & Name & True negative & True positif & Kelas precision \\
\hline 1. & Pred.negatif & 27 & 6 & $81.82 \%$ \\
2. & Pred.Positif & 23 & 44 & $65.67 \%$ \\
3. & Kelas recall & $54.00 \%$ & $88.00 \%$ & \\
\hline
\end{tabular}

Akurasi $=\frac{\mathrm{TP}+\mathrm{TN}}{\mathrm{TP}+\mathrm{TN}+\mathrm{FP}+\mathrm{FN}}=\frac{27+44}{27+44+23+6}=\frac{71}{100}=0.710=71.00 \%$

Precision $=\frac{\mathrm{TP}}{\mathrm{TP}+\mathrm{FP}}=\frac{44}{44+6}=\frac{44}{50}=0.880=88.00 \%$

Recall $=\frac{\mathrm{TP}}{\mathrm{TP}+\mathrm{FN}}=\frac{27}{27+23}=\frac{27}{50}=0.540=54.00 \%$

Berikut adalah tampilan kurva ROC yang akan dihitung nilai AUC-nya. Gambar 5 adalah kurva ROC untuk model Support Vector Machine (SVM). 


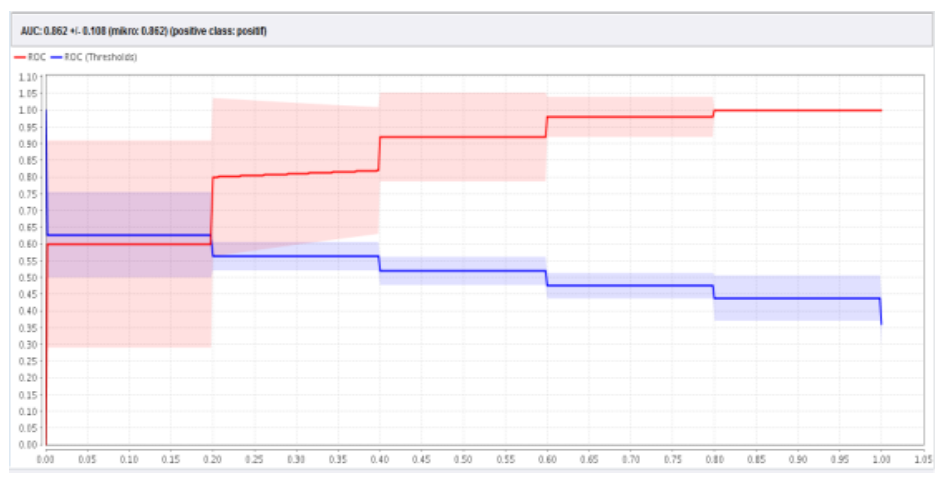

Gambar 4. Kurva ROC Model Support Vector Machine (SVM)

\section{Kesimpulan dan Saran}

\section{Kesimpulan}

Dalam penelitian ini dilakukan pengujian model dengan menggunakan Support Vector Machine dengan menggunakan data komentar review produk smartphone android dan blackberry yang positif maupun negatif. Model yang dihasilkan diuji untuk mendapatkan nilai accuracy, precision, recall dan AUC dari setiap algoritma sehingga didapat pengujian dengan menggunakan Support Vector Machine nilai accuracy adalah 71.00\%. Dengan demikian dari hasil pengujian model diatas dapat disimpulkan bahwa Support Vector Machine dapat memberikan pemecahan untuk permasalahan klasifikasi komentar review perbadingan whatsap dan BBM lebih akurat.

\section{Saran}

Agar penelitian ini bisa ditingkatkan, berikut adalah saran-saran yang diusulkan:

1. Menggunakan metode pemilihan fitur yang lain, seperti Chi Square, Gini Index, Mutual Information, dan lain-lain agar hasilnya bisa dibandingkan

2. Menggunakan data komentar review dari domain yang berbeda, misalnya komentar review restoran, komentar review film, review saham dan lain sebagainya.

\section{Daftar Pustaka}

Basari, A. S. H dan Hussin, B., Ananta, I. G. P., dan Zeniarja, J. (2013). Opinion Mining of Movie Review using Hybrid Method of Support Vector Machine and Particle Swarm Optimization. Procedia Engineering, 53, 453-462. doi:10.1016/j.proeng.2013.02.059.

Haddi, E., Liu, X., dan Shi, Y. (2014). The Role of Text Pre-processing in Sentiment Analysis. Procedia Computer Science, 17, 26-32. doi:10.1016/j.procs.2013.05.005.

Khan, K., Baharudin, B., dan Khan, A. (2014). Mining Opinion Components from Unstructured Reviews: A Review. Journal of King Saud University - Computer and Information Sciences. doi:10.1016/j.jksuci.2014.03.009.

Nugroho, A.W. (2008). Application of Support Vector Machine in Bioinformatics. Indonesian Scientific Meeting in Central Japan.

Weiss, S. M., Indurkhya, Nitin dan Zhang, Tong. (2010). Fundamentals of Predictive Text Mining. London: Springer-Verlag

Zhang, Z., Ye, Q., Zhang, Z., dan Li, Y. (2011). Sentiment classification of Internet restaurant reviews written in Cantonese. Expert Systems with Applications, 38(6), 7674-7682. doi:10.1016/j.eswa.2010.12.14. 